\title{
AN ANALYTICAL STUDY FOR THE POSITIVE EFFECTS OF THE INTEGRATION BETWEEN EGYPT AND SUDAN IN THE FIELD OF RED MEAT AND ITS EFFECT ON THE PRICE MEAT IN EGYPT.
}

Ahmed, N. A. ; M.A. Marry; A. S. Abdelwahab

Agricultural Economics Institute, Agricultural Research Center

$$
\begin{aligned}
& \text { دراسة تحليلية للآثار الإيجابية للكامل بين مصر والسودان فى مجال اللحوم }
\end{aligned}
$$

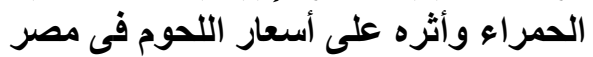

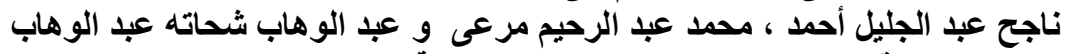

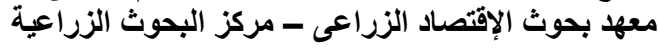

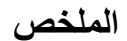

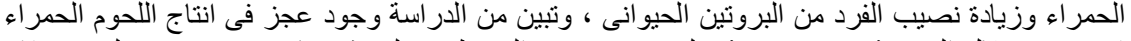

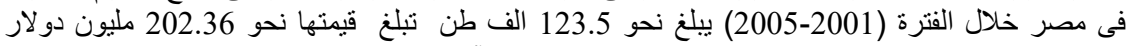

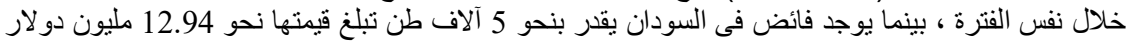

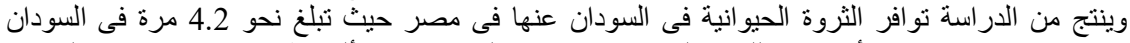

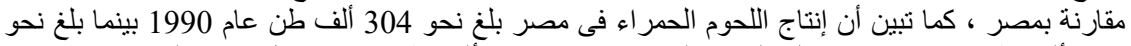

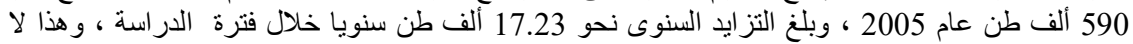

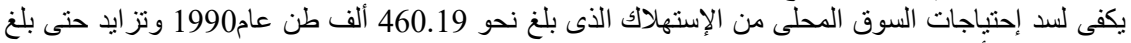

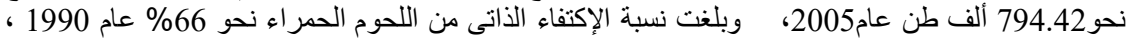

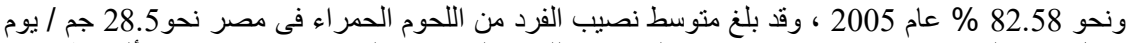

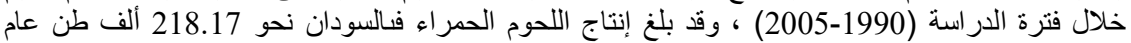

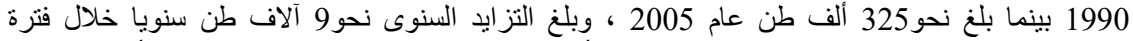

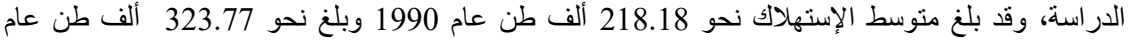

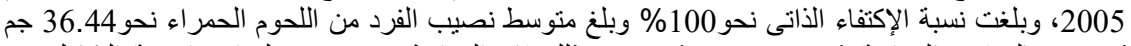

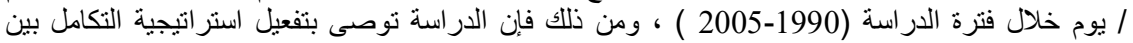

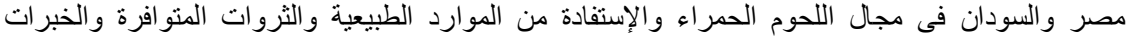

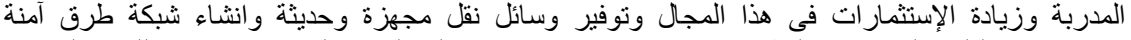

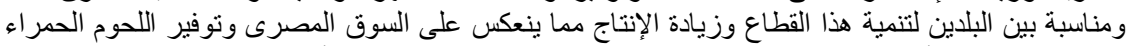

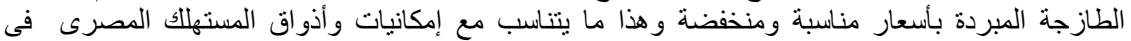
الإستهلاك لعدم تعود المستهلك المصرى على استهلاك اللحوم المستوردة المجمدة .

\section{المقدمة}

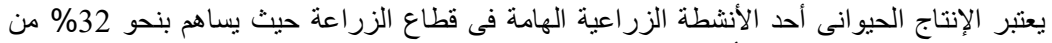

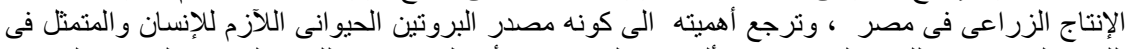

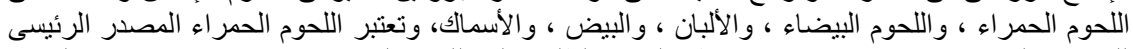

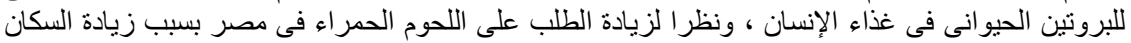

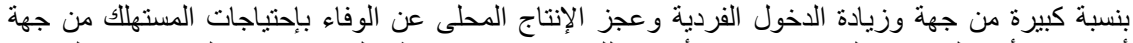

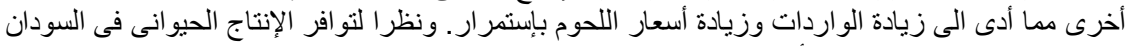

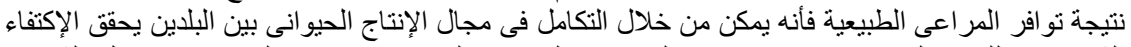

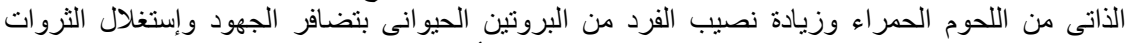

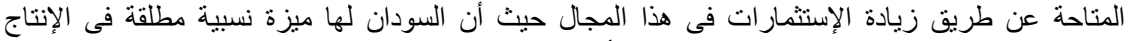

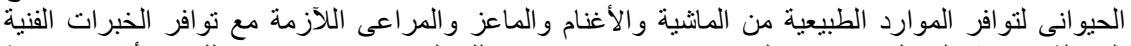

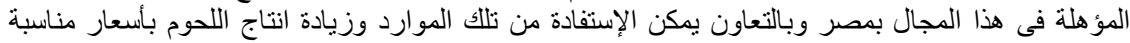


Ahmed, N. A. et al.

وبأقل التكاليف عن إنتاجها بمصر لإعتمادها على الأعلاف المصنعة غالية الثمن ،ويأتى ذلك بتفعيل

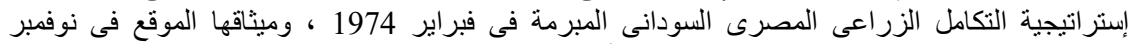

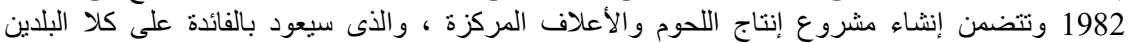

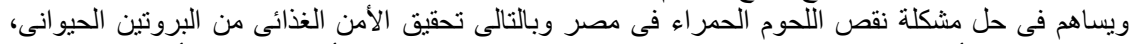

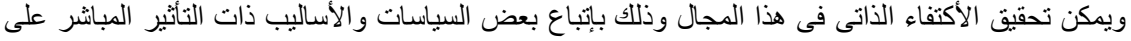

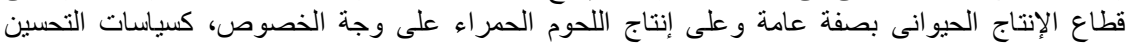

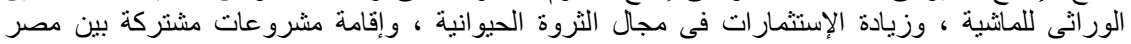

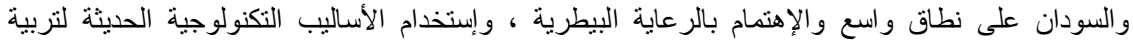

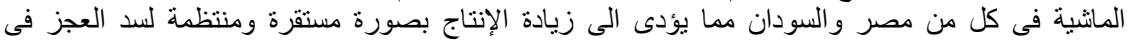

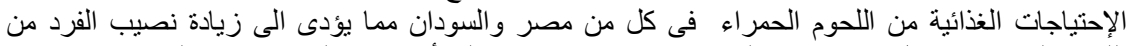

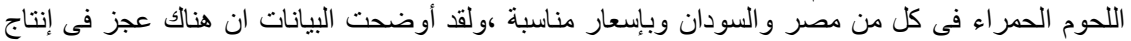

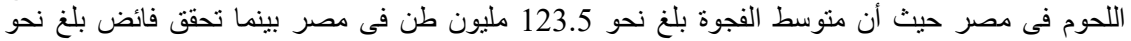

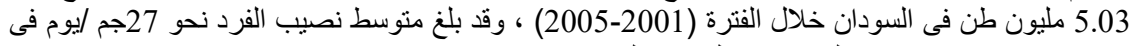

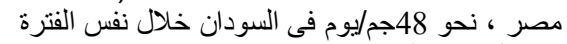

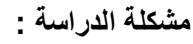

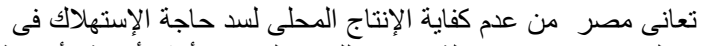

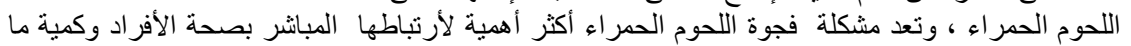

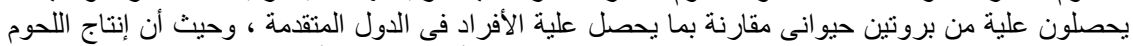

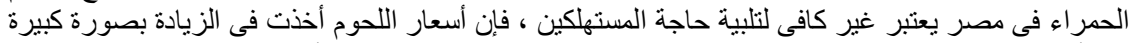

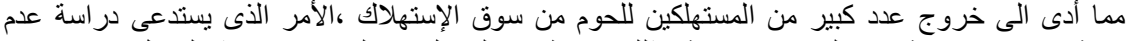

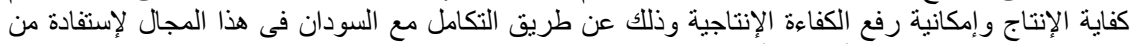

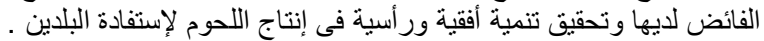

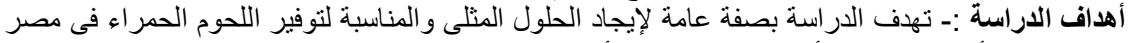

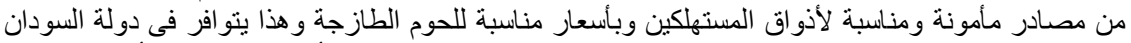

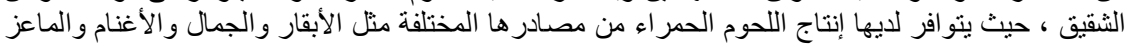

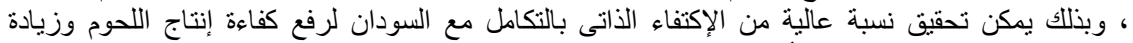

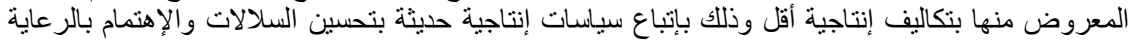

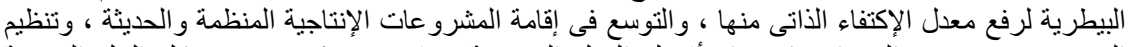

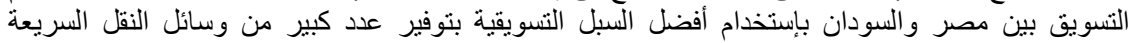

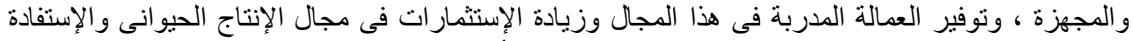
من الخبر ات المصرية فى هذا المجال مما يساعد على خفض أسعار الإلى اللحوم .

\section{الطريقة البحثية ومصادر البيانات}

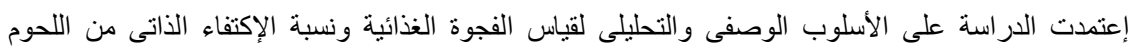

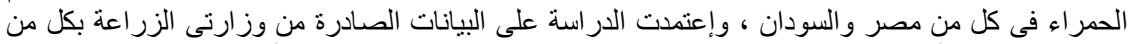

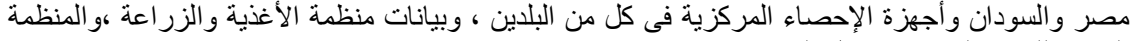

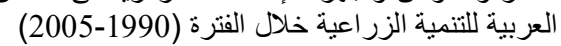

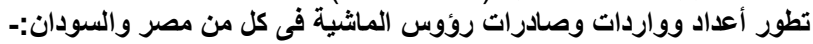

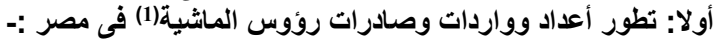

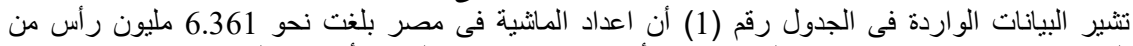

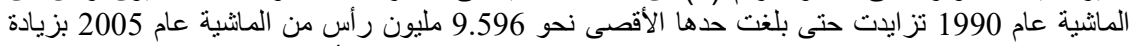

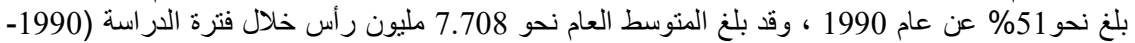

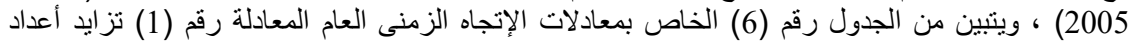

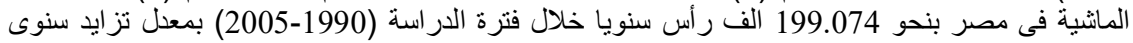

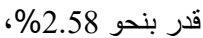

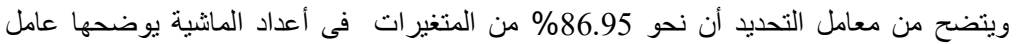

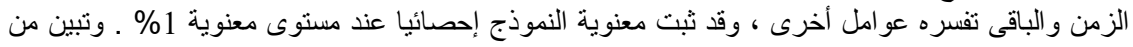


الواردات أنها بلغت نحو 2.581 الف رأس من الماثشية عام 1990 ، تزايدت وبلغت نحو 23901 ألفا

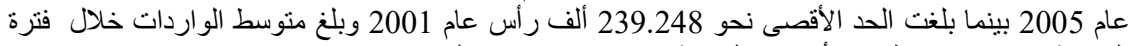

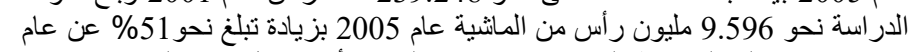

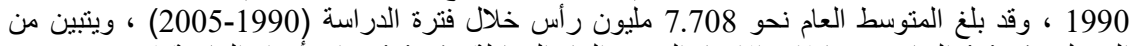

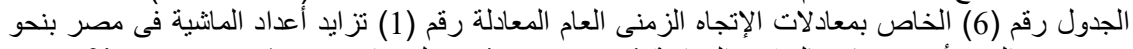

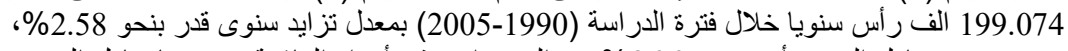

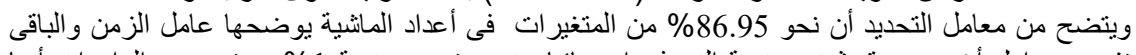

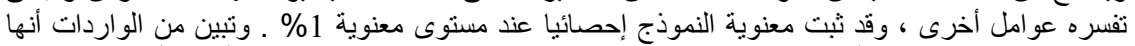

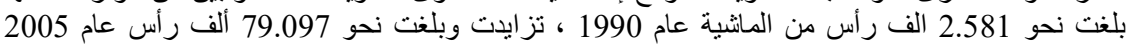

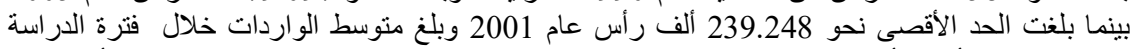

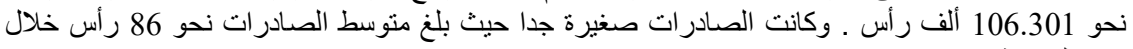

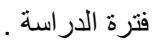

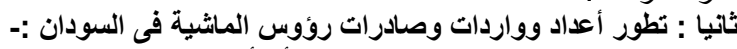

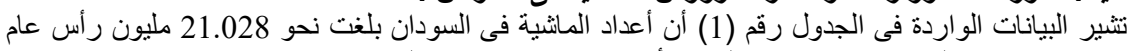

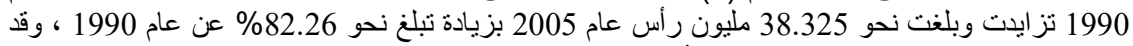

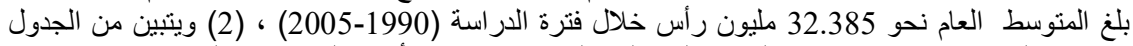

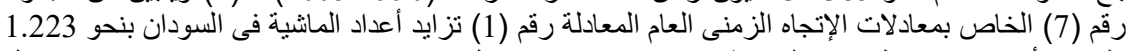

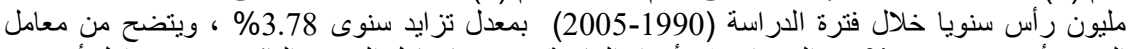

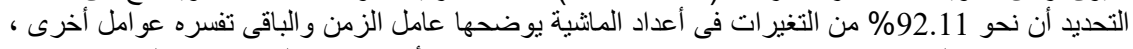

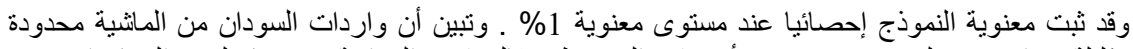

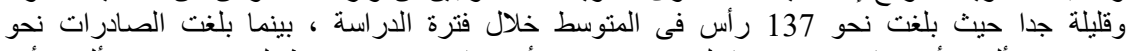

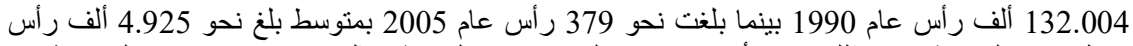

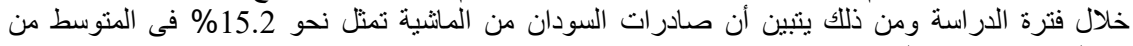

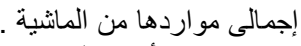

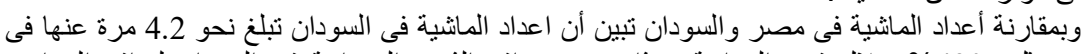

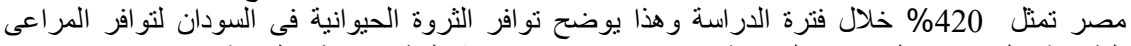

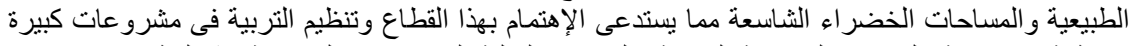

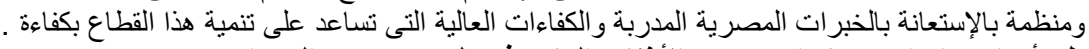

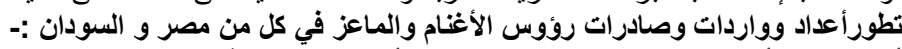

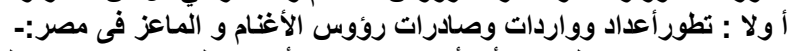

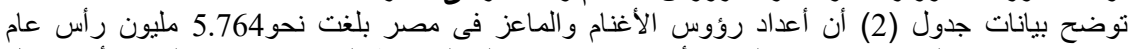

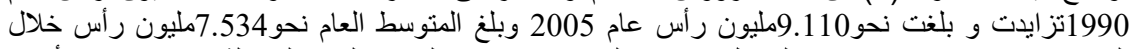

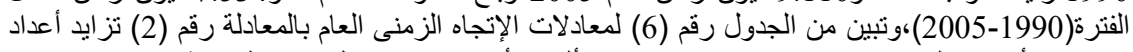

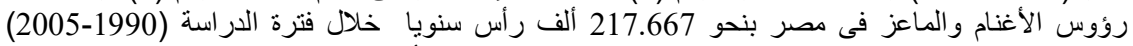

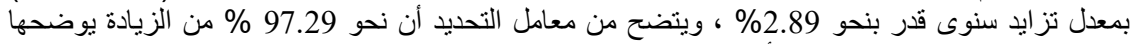

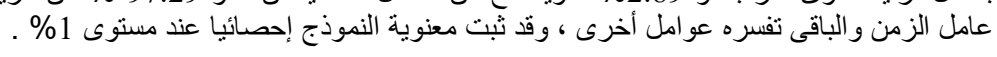

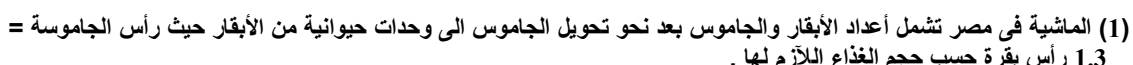

المصدر:- القاهمود . صادق العضيمى (دكتور) : إدارة الأعمال المزرعية ، مذكرات استنسيل - كلية زراعة - جامعة عين شمس ، عام

وتبين من الجدول (2) أن واردات مصر من الأغنام والماعز بلغت نحو 103.088 وألف رأس عام

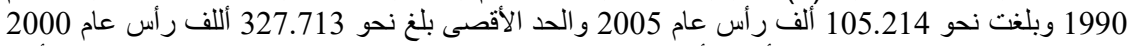

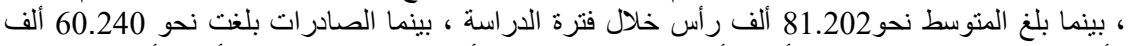

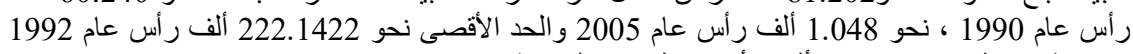
بمتوسط عام بلغ نحو 43.233 ألف رأس خلال فترة الدراسة 0 
Ahmed, N. A. et al.

جدول رقم (1) تظور أعداد وواردات وصادرات رؤوس الماشية فى مصر والسودان خلال الفترة (1990(2005

\begin{tabular}{|c|c|c|c|c|c|c|c|c|}
\hline \multicolumn{4}{|c|}{ السودان } & \multicolumn{4}{|c|}{ مصر } & \multirow[t]{2}{*}{ السنوات } \\
\hline إجمالى أعداد & صادرات & والماثشية & أعداد الماشية & إجمالى أعداد & صادرات & واردات & أعداد الماشية & \\
\hline 21.015 .496 & 13.004 & 700 & 21.027 .800 & 6.363 .723 & صفر & 2.581 & 6361.142 & 1990 \\
\hline 21.616 .533 & 13.967 & 500 & 21.630 .000 & 6.867 .992 & صفر & 2.507 & 6865.485 & 1991 \\
\hline 25.082 .400 & 10.000 & 400 & 25.092 .2000 & 7.094 .801 & 133 & 10.434 & 7084.500 & 1992 \\
\hline 27.561 .200 & 10.000 & 200 & 27.571 .00 & 7.307 .889 & 20 & 105.849 & 7202.060 & 1993 \\
\hline 28.990 .000 & 10.000 & صفز & 29.000 .000 & 6.986 .757 & صفر & 201.684 & 6785.073 & 1994 \\
\hline 30.073 .930 & 3.170 & 100 & 30.077 .000 & 7.103 .171 & صفر & 184.226 & 6918.945 & 1995 \\
\hline 31.658 .908 & 10.092 & صفر & 31.669 .000 & 6.932 .016 & 1.200 & 47.591 & 6885.625 & 1996 \\
\hline 33.099 .960 & 3.040 & صفر & 33.103 .000 & 7.198 .918 & صفر & 56.726 & 7142.192 & 1997 \\
\hline 34.581 .133 & 2.867 & صفر & 34.584 .000 & 7.401 .956 & صفر & 91.000 & 7310.956 & 1998 \\
\hline 35.824 .994 & 6 & صفر & 3.825 .000 & 7.955 .247 & صفر & 209.057 & 7746.190 & 1999 \\
\hline 37.092 .917 & 163 & 80 & 37.093 .000 & 8.156 .461 & 16 & 233.524 & 7922.953 & 2000 \\
\hline 38.325 .000 & صفر & صفز & 38.325 .000 & 8.632 .236 & صفر & 239.248 & 8392.988 & 2001 \\
\hline 38.181 .147 & 1.853 & صفر & 38.183 .000 & 8.767 .870 & صفر & 152.870 & 8615.000 & 2002 \\
\hline 38.324 .864 & 266 & 130 & 38.325 .000 & 9.171 .517 & صفر & 34.417 & 9137.100 & 2003 \\
\hline 38.325 .000 & صفر & صفر & 38.325 .000 & 9.417 .500 & صفر & 50.000 & 9367.500 & 2004 \\
\hline 38.324 .696 & 379 & 75 & 38.325 .000 & 9.675 .097 & صفر & 79.097 & 9596.000 & 2005 \\
\hline 32.379 .886 & 4.925 & 137 & 32.384 .675 & 7.814 .572 & 86 & 106.301 & 7708.357 & المتو سط \\
\hline
\end{tabular}

1)FAOSTAT , Food and Agricultural Organization of the United Nations http://food, stat .external .fao.org.

2) جمهورية مصر العربية، الجهاز المركزى للتعبئة العامة والاحصاء ، نثرات احصاءات الثروة الحيوانية ، نثرات التجارة الخارجية

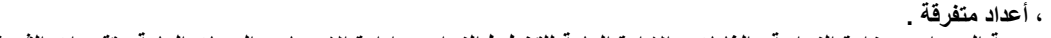

3) جمهورية السودان ، وزارة الزئل الزراعة والغابات ، الادارة العامة للتخطيط الزراعى ،ادارة الاحصاء ، السمات العامة وتقليرات الثروة

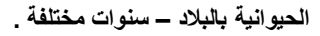

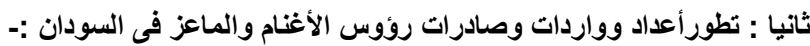

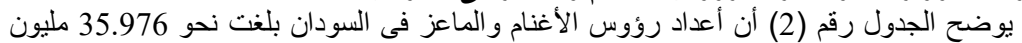

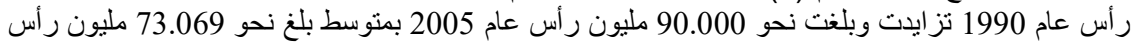

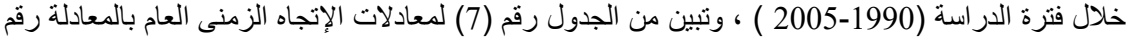

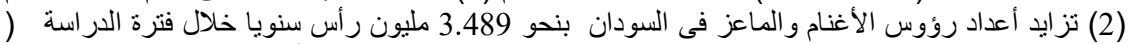

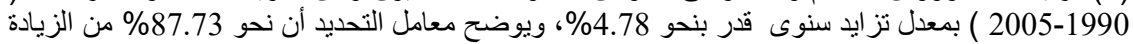

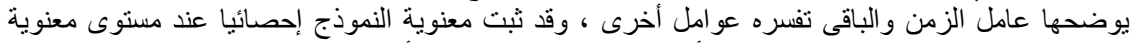

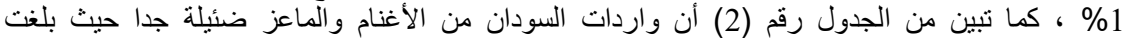

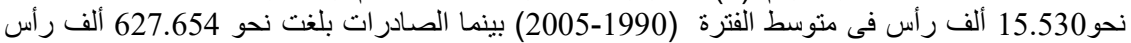

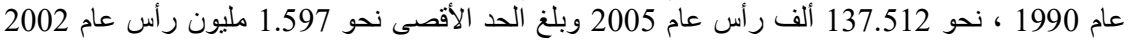

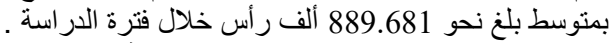

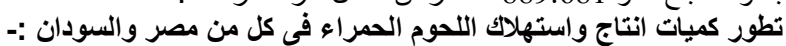

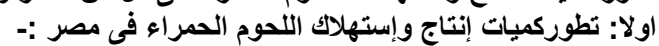

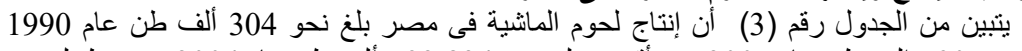

تز ايد وبلغ نحو 590 الف طن عام 2005 بحد أقصى بلغ نحو 593.834 ألف طن عام 2004 بمتوسط بلغ

نحو 452.316 ألف طن خلال الفترة (1990-2005) ، وتبين من الجدول رقم (6) لمعادلات الإتجاه العام

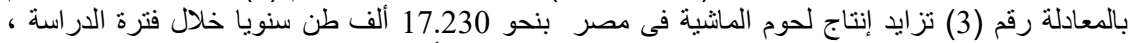

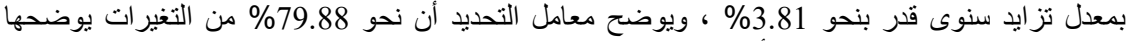

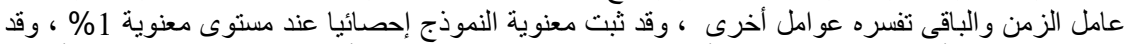

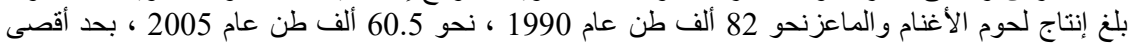

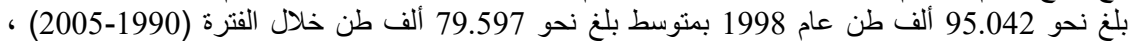
وتبين من الجدول رقم (6) بالمعادلة رقم (4) تناقص إنتاج لحوم الأغنام والماعز فى مصر بنحو 1.227 طن 


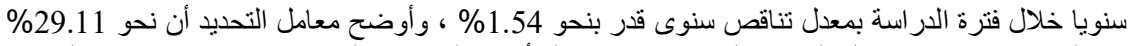

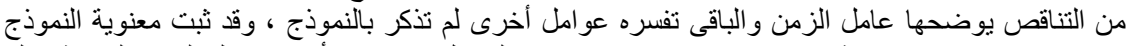

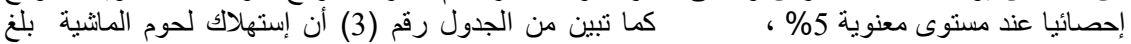

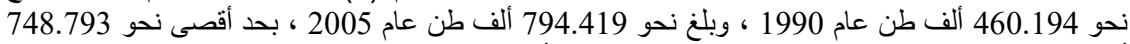

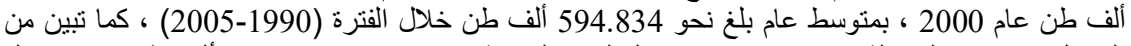

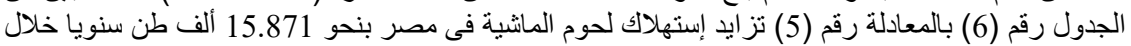

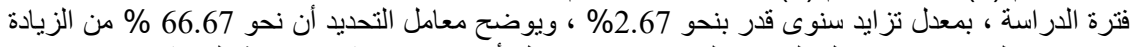

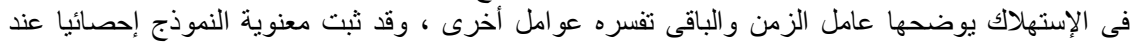

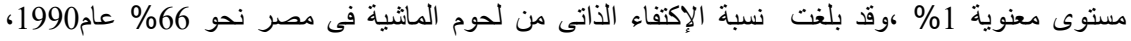

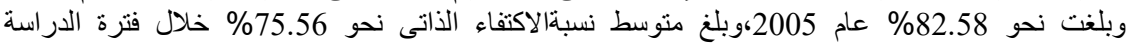

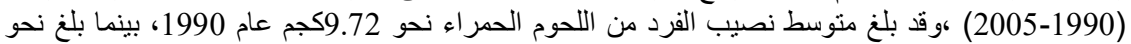

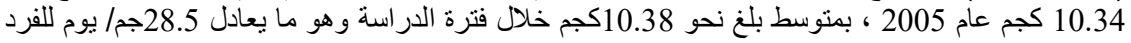

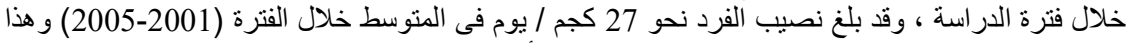

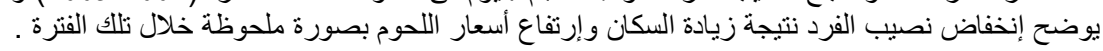

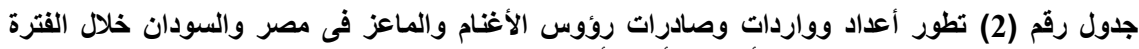
(2005-1990) (الأعداد بالألف رأس ) (أسوان )

\begin{tabular}{|c|c|c|c|c|c|c|c|c|}
\hline \multicolumn{4}{|c|}{ السودان } & \multicolumn{4}{|c|}{ مصر } & \multirow[t]{2}{*}{ السنوات } \\
\hline الأغمالى أعداد الماعز & صادر ات & واردات & |أعداد الاغنام & الأغمالى أعداد الماعز & صادر ات & واردات & أعداد الاغنام & \\
\hline 35348.346 & \begin{tabular}{|l|}
627.654 \\
\end{tabular} & صفر & 35976.000 & 5806.483 & 60.24 & 103.088 & 5763.635 & 1990 \\
\hline 41563.000 & 400.000 & صفر & 41963.000 & 5822.864 & 118.588 & 37.319 & 5904.133 & 1991 \\
\hline 478711.000 & 500.000 & صفر & 49211.000 & 5929.812 & 222.142 & 11.756 & 6140.198 & 1992 \\
\hline 57944.700 & 600.000 & صفر & 58544.700 & 6568.087 & 192.297 & 36.868 & 6723.516 & 1993 \\
\hline 69374.800 & 1.089 .200 & صفر & 70464.000 & 7006.625 & 4.284 & 8.000 & 7002.909 & 1994 \\
\hline 71503.080 & \begin{tabular}{|l|}
891.920 \\
\end{tabular} & صفر & 72395.000 & 7427.408 & 150 & 76.000 & 7351.558 & 1995 \\
\hline 71173.072 & 1.244 .928 & صفر & 72418.000 & 7333.838 & 32.722 & 15.000 & 7351.560 & 1996 \\
\hline 74870.183 & 1.056 .984 & 55.167 & 75872.000 & 7471.753 & 20.258 & 44.659 & 7447.352 & 1997 \\
\hline 77688.208 & 1.233 .290 & 60.498 & 78861.000 & 7624.280 & 22.076 & 33.532 & 7612.824 & 1998 \\
\hline 80796.404 & 1.408 .210 & 56.614 & 82148.000 & 7864.203 & صفر & 165.326 & 7698.877 & 1999 \\
\hline 84089.806 & 588.725 & 35.531 & 84643.000 & 8221.600 & صفز & 327.713 & 7893.887 & 2000 \\
\hline 86988.260 & 6.740 & صفر & 86995.000 & 8311.785 & 4.000 & 147.542 & 8168.243 & 2001 \\
\hline 88064.542 & 1.596 .722 & 40.264 & 89621.000 & 8754.895 & 300 & 68.195 & 8687.000 & 2002 \\
\hline 88596.996 & 1.403 .012 & 8 & 90000.000 & 8856.311 & 12.707 & 119.018 & 8750.000 & 2003 \\
\hline 88550.146 & 1.450 .000 & 146 & 90000.000 & 8931.088 & 912 & صفر & 8932.000 & 2004 \\
\hline 89862.737 & \begin{tabular}{|l|}
137.512 \\
\end{tabular} & 249 & 90000.000 & 9214.166 & 1.048 & 105.214 & 9110.000 & 2005 \\
\hline 72195.330 & 889.681 & 15.530 & 73069.481 & 7571.575 & 43.233 & 81.202 & 7533.606 & المتوسط \\
\hline
\end{tabular}

1)FAOSTAT , Food and Agricultural , Organization of the United Nations .

http://food stat .external .fao.org .

2) جمهورية مصر العربية، الجهاز المركزى للتعبئة العامة والاحصاء ، نثرات احصاءات لثروة الحيوانية ، نثرات التجارة الخارجية

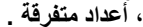

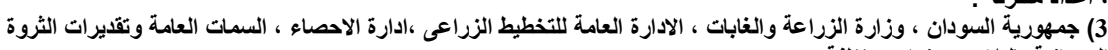

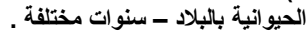

جدول رقم (3) تطور كميات إنتاج و إستهلاك لحوم الماثية والأغنـام والمـاعز في مصر خلالال القترة (1990-

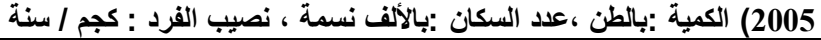

\begin{tabular}{|c|c|c|c|c|c|c|c|c|c|c|}
\hline الفُصبي & الالحرد من & إلتأجنام & الفرد من & عدد السكان & الإكاتفاء & الإستهلاكك & الصادرات & الو اردات & المناجنية لحوم & |السنوات \\
\hline 9.72 & 1.47 & 82000 & 8.25 & 55768 & 66.06 & 460194 & 5565 & 161 & 304000 & 1990 \\
\hline 9.66 & 1.30 & 74000 & 8.36 & 56957 & 70.35 & 476196 & 1117 & 142313 & 335000 & 1991 \\
\hline 9.61 & 1.34 & \begin{tabular}{|l|}
77750 \\
\end{tabular} & 8.27 & \begin{tabular}{|l|}
58132 \\
\end{tabular} & 71.25 & 480978 & 4203 & 142501 & 342680 & 1992 \\
\hline
\end{tabular}


Ahmed, N. A. et al.

\begin{tabular}{|c|c|c|c|c|c|c|c|c|c|c|}
\hline 10.24 & 1.39 & 82500 & 8.85 & 59297 & 68.82 & 524588 & 3692 & 167280 & 361000 & 1993 \\
\hline 10.37 & 1.45 & 87450 & 8.92 & 60483 & 70.89 & 539148 & 2086 & 159056 & 382178 & 1994 \\
\hline 10.17 & 1.48 & 91150 & 8.69 & 61638 & 73.54 & 535595 & 1386 & 143124 & 393857 & 1995 \\
\hline 10.44 & 1.44 & 90675 & 9.00 & 62823 & 80.09 & 565290 & 1005 & 113542 & 452753 & 1996 \\
\hline 11.33 & 1.46 & 93186 & 9.87 & 64019 & 79.67 & 631993 & 1390 & 129864 & 503519 & 1997 \\
\hline 11.49 & 1.46 & 95042 & 10.03 & 65237 & 79.23 & 654076 & 1106 & 13928 & 518254 & 1998 \\
\hline 11.62 & 1.21 & 80398 & 10.41 & 66489 & 73.62 & 692369 & 758 & 183385 & 509742 & 1999 \\
\hline 12.16 & 1.11 & 75000 & 11.05 & 67784 & 72.60 & 748793 & 767 & 205966 & 543594 & 2000 \\
\hline 8.96 & 1.13 & 77810 & 7.83 & 69124 & 80.44 & 541189 & 834 & 106714 & 435309 & 2001 \\
\hline 9.62 & 1.11 & 78134 & 8.51 & 70507 & 75.92 & 600125 & 1056 & 145578 & 455603 & 2002 \\
\hline 9.91 & 0.98 & 70596 & 8.93 & 71931 & 80.31 & 64162 & 1500 & 127928 & 515.734 & 2003 \\
\hline 10.46 & 0.78 & 57358 & 9.68 & 73390 & 83.61 & 710222 & 1372 & 117760 & 593834 & 2004 \\
\hline 10.34 & 0.81 & 60500 & 9.53 & 74953 & 82.58 & 714419 & 1423 & 125842 & 590.000 & 2005 \\
\hline 10.38 & 1.23 & 79597 & 9.16 & 64907 & 75.56 & 594834 & 1829 & 144346 & 452.316 & المتوسط \\
\hline
\end{tabular}

1)FAOSTAT , . Food and Agricultural Organization of the United Nations , stat .external .fao.org. 2) جمهورية مصر العربية، الجهاز المركزى للتعبئة العامة والاحصاء ، نثرات احصاءات الثروة الحيوانيخة ، نثرات التجارة الخارجية

، أعداد متفرقة .

ثانيا: تطوركميات إنتاج و إستهلاك اللحوم الحمراء فى السودان :-

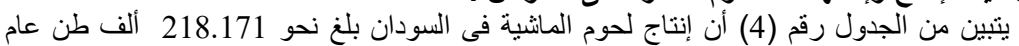

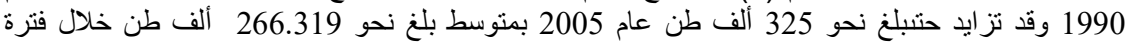

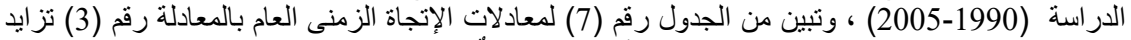

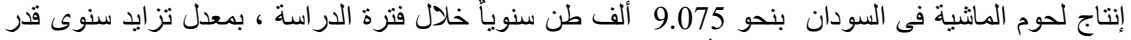

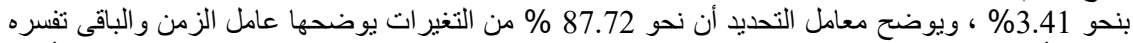

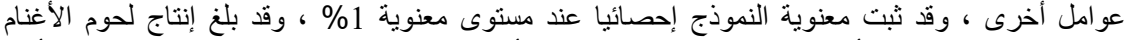

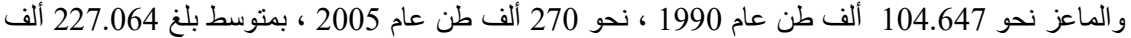

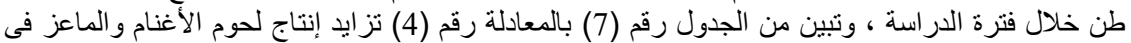

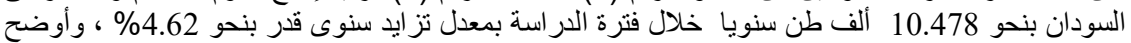

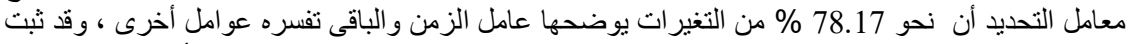

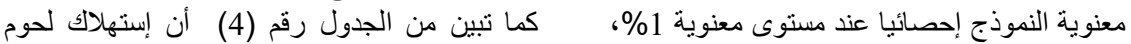

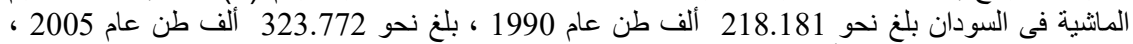

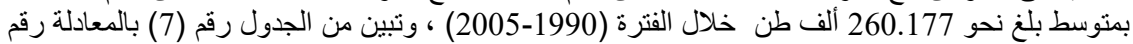

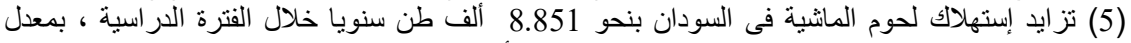

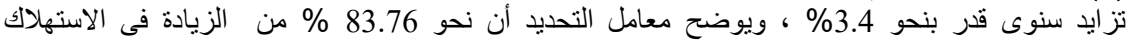

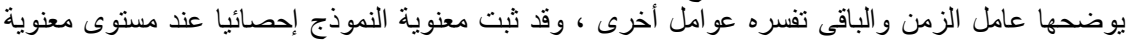

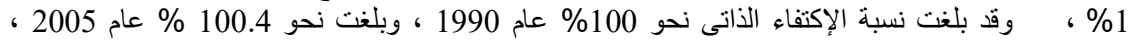
وبلغت أقصاها نحو 106.26 \% بلغة عام 1996 بمتوسط بلغ نحو 102.43\% خلال فترة الدراسة (1990-

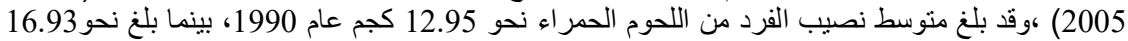

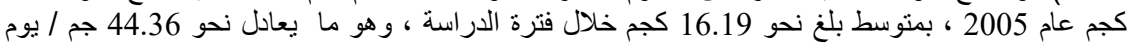
للفرد خلال فترة الدر اسة ، وقد بلغ نصيب الفرد نحو 48كجم/يوم فى المتوسط خلال الفترة (2001-2005) 0

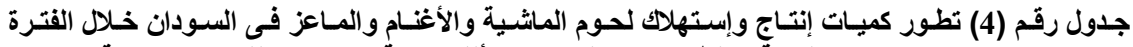

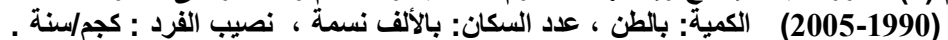

\begin{tabular}{|c|c|c|c|c|c|c|c|c|c|c|}
\hline الحمبالى الفرد من & الفرد من & |الأغناج لحوم & الفرد من & عدد السكان & \% الذانتى للإكفاء & الإستهلاك & الصادرات & الواردات & المناج لحوم & |السنوات \\
\hline 12.95 & 4.20 & 104647 & 8.75 & 24927 & 100.00 & 218181 & صفر & 10 & 218171 & 1990 \\
\hline 13.95 & 4.87 & 124078 & 9.08 & 25493 & 100.00 & 231432 & صفر & صفز & 231432 & 1991 \\
\hline
\end{tabular}


J. Agric. Sci. Mansoura Univ., 32 (1), January, 2007

\begin{tabular}{|c|c|c|c|c|c|c|c|c|c|c|}
\hline 14.49 & 5.86 & 153000 & 8.63 & 26105 & 100.29 & 225350 & 650 & صفر & 226000 & 1992 \\
\hline 14.50 & 6.69 & 179000 & 7.81 & 26752 & 102.93 & 208871 & 6129 & صفر & 215000 & 1993 \\
\hline 15.07 & 7.47 & 204867 & 7.60 & 27415 & 101.93 & 208336 & 4047 & 35 & 212348 & 1994 \\
\hline 16.22 & 8.44 & 236913 & 7.78 & 28077 & 102.90 & 218417 & 6502 & 169 & 224750 & 1995 \\
\hline 15.84 & 8.43 & 242320 & 7.41 & 28736 & 106.26 & 213068 & 13416 & 79 & 226405 & 1996 \\
\hline 16.79 & 8.67 & 255000 & 8.12 & 29397 & 104.74 & 238675 & 11816 & 491 & 250000 & 1997 \\
\hline 17.13 & 8.78 & 263800 & 8.35 & 30062 & 105.54 & 251089 & 14662 & 751 & 265000 & 1998 \\
\hline 17.02 & 8.34 & 256400 & 8.68 & 30741 & 103.440 & 266811 & 9650 & 461 & 276000 & 1999 \\
\hline 17.45 & 8.30 & 261000 & 9.15 & 31437 & 102.87 & 287731 & 8566 & 297 & 296000 & 2000 \\
\hline 18.22 & 8.46 & 272000 & 9.76 & 32151 & 101.96 & 313837 & 6455 & 292 & 320000 & 2001 \\
\hline 17.85 & 8.21 & 270000 & 9.64 & 32878 & 102.58 & 316824 & 8370 & 194 & 325000 & 2002 \\
\hline 17.46 & 8.03 & 270000 & 9.43 & 33610 & 102.53 & 316987 & 8083 & 70 & 325000 & 2003 \\
\hline 17.28 & 7.86 & 270000 & 9.42 & 34333 & 100.48 & 323449 & 1629 & 78 & 325000 & 2004 \\
\hline 16.93 & 7.70 & 270000 & 9.23 & 35086 & 100.38 & 323772 & 1317 & 89 & 325000 & 2005 \\
\hline 16.19 & 6.41 & 227064 & 8.72 & 29825 & 102.43 & 260177 & 6331 & 189 & 266319 & المتوسط \\
\hline
\end{tabular}

1)FAOSTAT, Food and Agricultural ${ }_{s}$ Organization of the United Nations .

http://food , stat .external .fao.org.

2) جمهورية السودان ، وزارة الززراعة والغابات ، الادارة العامة للتخطيط الزراعى ،ادارة الاحصاء ، السمات العامة وتقايرات الثروة

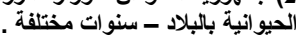

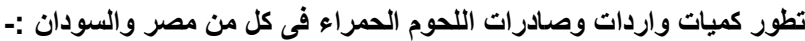

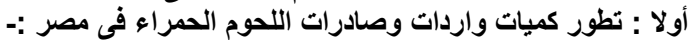

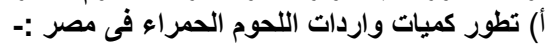

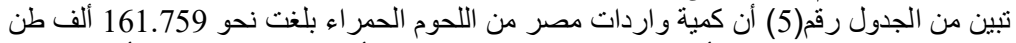

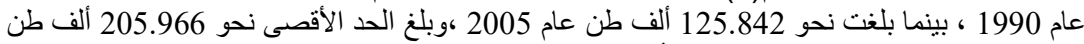

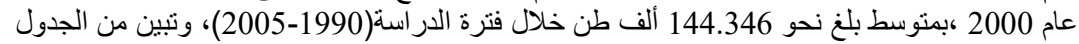

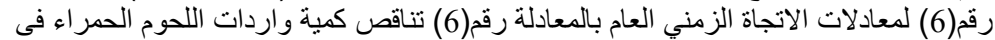

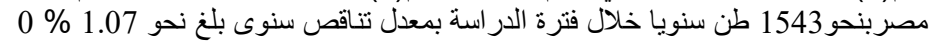

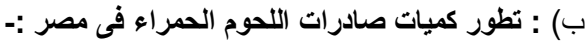

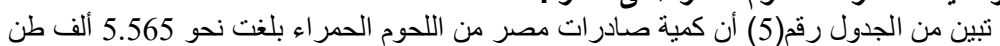

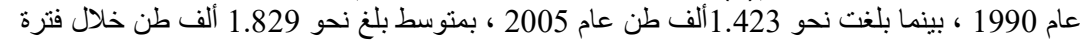

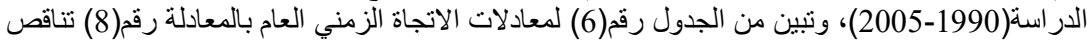

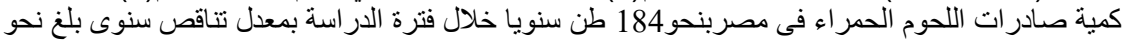
0 \% 10.1

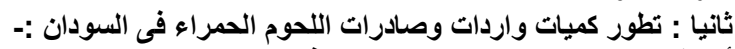

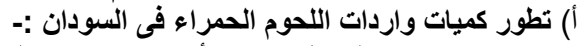

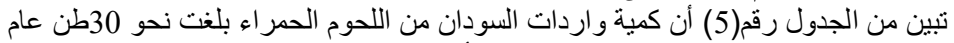

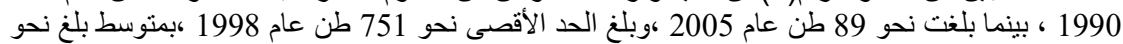

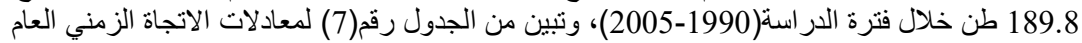

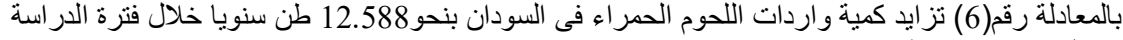

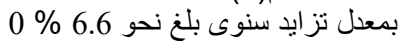
ب) : تطور كميات صنادرات اللحوم الحمراء فئ فئ السودان:-

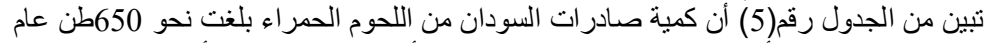

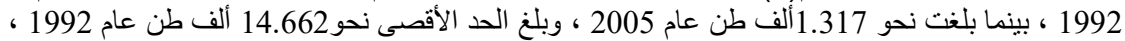

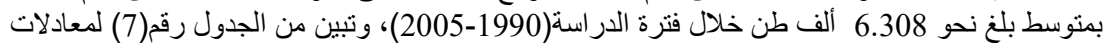

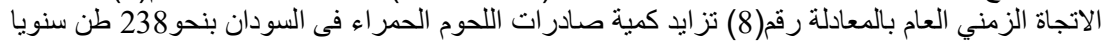

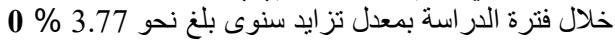
(

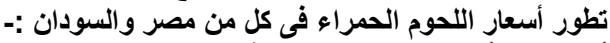

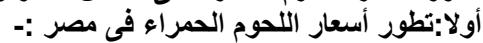

الجدول رقم (5) أن أسعار واردات اللحوم فى مصر قد بلغت نحو 1.218 دولار للكيلو جرام عام 1990 بينما 
Ahmed, N. A. et al.

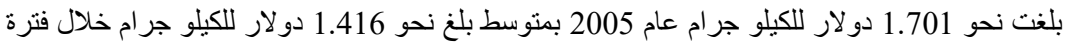

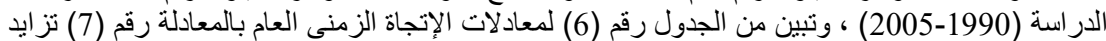

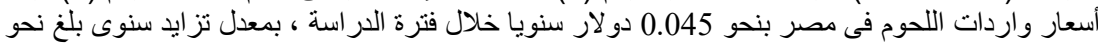

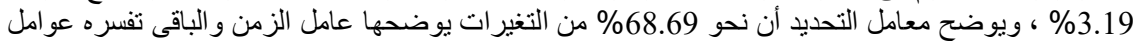

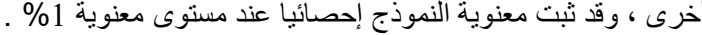

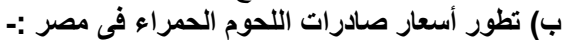

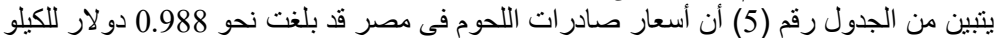

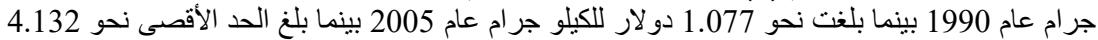

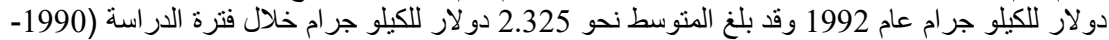

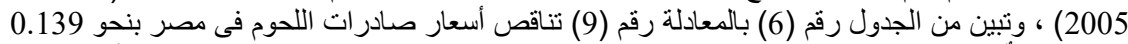

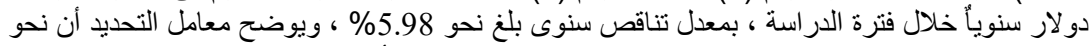
39.11\% من التغير ات يوضحها عامل الزمن و الباقى تفسره عو امل أخرى ، وقد ثبت معنوية النموذج إحصائيا

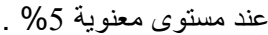
ثانيا :تطور أسعار اللحوم الحمراء فئو في السودان :

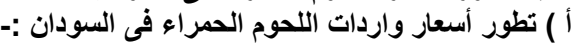

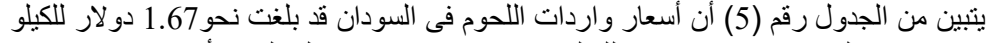

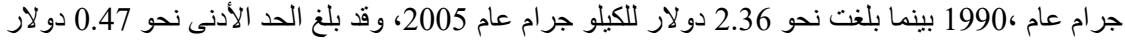

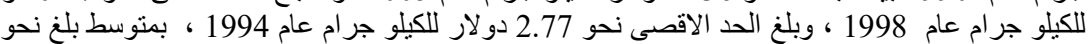

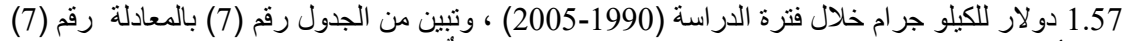

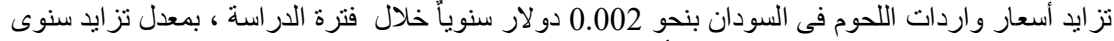

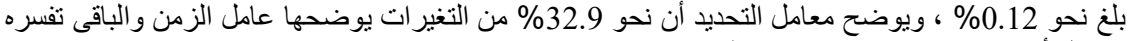
عو امل أخرى ، وقد ثبت عدم معنوية النموذج إحصائيا .

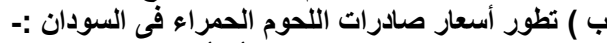

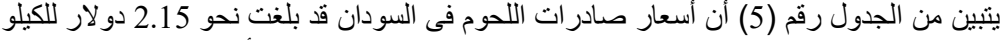

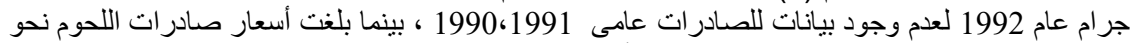

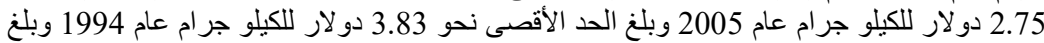

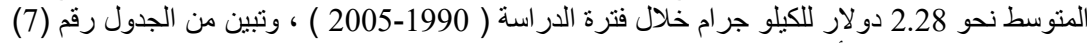

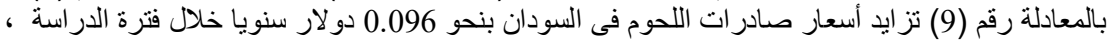

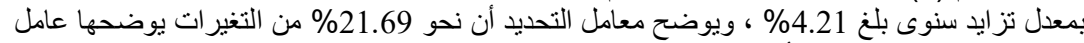

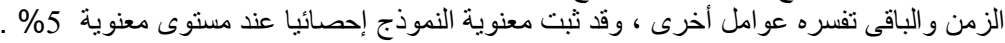

جدول رقم (5) كمية وقيمة صادرات وواردات اللحوم فى مصر والسودان خلال الفترة(1990-2005) الكمية:

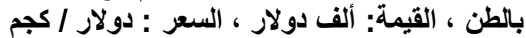

\begin{tabular}{|c|c|c|c|c|c|c|c|c|c|c|c|c|}
\hline \multicolumn{6}{|c|}{ السودان } & \multicolumn{6}{|c|}{ مصر } & \multirow[t]{4}{*}{ |السنوات } \\
\hline أسعار & قيمة & كمية & أسعار & قيمة & كمية & أسعار & قيمة & كمية & أسعار & قيمة & كمية & \\
\hline |الصادرا & صادر & صادر & ה19 & واردات & & & عادراد & صادرات & الواردات & واردات & واردات & \\
\hline & اللحوم & اللحوم & & اللحوم & اللحوم & & اللحوم | & اللحوم | & & اللحوم & اللحوم & \\
\hline صفر & صفر & صفر & 1.67 & 50 & 30 & 0.998 & 5555 & 5565 & 1.218 & 197085 & 161759 & 1990 \\
\hline صفر & صفر & صفر & صفر & صفر & صفر & 2.950 & 3295 & 1117 & 1.350 & 147289 & 142313 & 199 \\
\hline 2.15 & 1400 & 650 & صفر & صفر & صفر & 4.132 & 17368 & 4203 & 0.936 & 133402 & 142501 & 1992 \\
\hline 3.04 & 18649 & 6129 & صفر & صفر & صفر & 4.030 & 14877 & 3692 & 1.018 & 170348 & 167280 & 1993 \\
\hline 3.83 & 15502 & 4047 & 2.77 & 97 & 35 & \begin{tabular}{|l|}
4.059 \\
\end{tabular} & \begin{tabular}{|l|l|}
8467 \\
\end{tabular} & 2086 & 1.136 & 180631 & 159056 & 1994 \\
\hline 2.81 & 18292 & 6502 & 1.65 & 279 & 169 & \begin{tabular}{|l}
2.710 \\
\end{tabular} & 3756 & 1386 & 1.497 & 214192 & 143124 & 1995 \\
\hline 2.46 & 32992 & 13416 & 3.01 & 238 & 79 & 2.266 & 2277 & \begin{tabular}{|l|}
1005 \\
\end{tabular} & 1.547 & 17565 & 113542 & 1996 \\
\hline 2.19 & 25901 & 11816 & 0.84 & \begin{tabular}{|l|}
414 \\
\end{tabular} & 491 & 2.762 & 3839 & $\begin{array}{l}1390 \\
\end{array}$ & 1.500 & 194849 & 129864 & 1997 \\
\hline
\end{tabular}


J. Agric. Sci. Mansoura Univ., 32 (1), January, 2007

\begin{tabular}{|c|c|c|c|c|c|c|c|c|c|c|c|}
\hline 2.14 & 387 & 14662 & 0.47 & 353 & 751 & 2.175 & 2405 & 1106 & 1.658 & \begin{tabular}{|l|l|l|}
227056 & 136928 \\
\end{tabular} & 19 \\
\hline 2.33 & 474 & 9650 & 2.11 & 971 & 461 & 1.727 & 1309 & 758 & 1.529 & \begin{tabular}{|l|l|l|}
804703385 \\
\end{tabular} & 1999 \\
\hline 2.45 & 21024 & 8566 & 0.74 & 220 & 297 & 2.274 & 1744 & 767 & 1.477 & \begin{tabular}{|l|l|}
304249 & 205966 \\
\end{tabular} & 2000 \\
\hline 2.27 & 14630 & 6455 & 0.78 & 227 & 292 & 1.964 & 1638 & 834 & 1.597 & \begin{tabular}{|l|l|}
170461 & 106714 \\
\end{tabular} & 2001 \\
\hline 2.38 & 19891 & 8370 & 1.16 & 225 & 194 & 1.669 & 1762 & 1056 & 1.635 & \begin{tabular}{|l|l|}
238080 & 145578 \\
\end{tabular} & 2002 \\
\hline 2.85 & 23050 & 8083 & 1.93 & 135 & 70 & 1.327 & 1990 & 1500 & 1.476 & \begin{tabular}{|l|l|}
188772 & 127928 \\
\end{tabular} & 2003 \\
\hline 2.75 & 3491 & 1269 & 2.36 & 184 & 78 & 1.077 & 1478 & 1372 & 1.701 & 2003 & 2004 \\
\hline 2.75 & 3624 & 1317 & 2.36 & 210 & 89 & 1.077 & 1533 & 1423 & 1.701 & $214114 \mid 125842$ & 2005 \\
\hline 2.28 & 15769 & 6308 & 1.37 & 225.2 & 89.8 & 2.325 & 4581 & 1829 & 1.416 & $202314 \mid 144346$ & |المتوس \\
\hline
\end{tabular}

1)FAOSTAT, Food and Agricultural Organization of the United Nations .

http://food, stat .external .fao.org.

2) جمهورية مصر العربية، الجهاز المركزى للتعبئة العامة والاحصاء ، نثرات احصاءات الثروة الحيوانية ، نثرات التجارة الخارجية

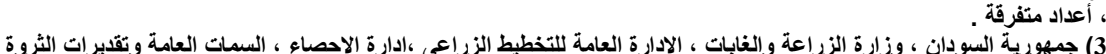

الحيو انية بالبلاد - سنوات مختلفة .

\begin{tabular}{|c|c|c|c|c|c|}
\hline | السنولى النمو & $2 \jmath$ & i & $ت$ & ه الزمنى العام لإنتاج اللحوم فحى مص & * جبيان \\
\hline 2.58 & 86.95 & 93.243 & 9.656 & ص8 هـ = 6016231+69073.6س هـ & | (1) أعداد الماشية \\
\hline 2.89 & 97.29 & 502.277 & 22.412 & ص8 هـ & | (2) أعداد الأغنام و الماعز \\
\hline 3.81 & 79.88 & 55.57 & 7.455 & ص 8= = 17229.66 س سـ & (3) إنتاج لحوم الماشبة \\
\hline $1.54-$ & 29.11 & 5.747 & $2.397(-)$ & صه هـ = 1226.53-90022.3س هـ & (4) إنتاج لحوم الاغنام والماعز \\
\hline 2.67 & 66.67 & 28.01 & 5.292 & صه هـ = 459931.5+45870.83س هـ & 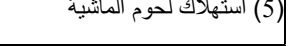 \\
\hline $1.07-$ & 6.86 & 1.188 & $1.09-$ & صه هـ = 1542.88-157460.7س هـ & |6 (6) كبية واردات لحوم الماتنية \\
\hline 3.18 & 68.69 & 30.713 & 5.542 & ص ${ }^{8}$ & |(7) اسعار واردات لحوم الماتثية \\
\hline $84.36-$ & 7.84 & 1.191 & $2.988-$ & صه هـ = 184.053-3393.2س هـ & | (8) كمية صادرات لحوم الماتشية \\
\hline $5.97-$ & 39.11 & 8.991 & $2.998(-)$ & صنه= = 0.1387-3.5037س هـ & |(9) اسعار صادرات لحوم المانُشية \\
\hline
\end{tabular}

جدول رقم (7) معادلات الإتجاه الزمنى العام لإتتاج اللحوم في اللسودان خلال الفترة (19902005)

\begin{tabular}{|c|c|c|c|c|c|}
\hline | النمو المعنوى & $2 J$ & ف & $ت$ & المعادلة & |ألبيان \\
\hline 3.78 & 92.11 & 163.419 & $\begin{array}{c}* * \\
12.748 \\
\end{array}$ & ص8 هـ = 1223.335+21986.325س هـ & 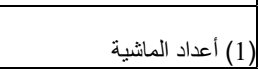 \\
\hline 4.78 & 87.73 & 100.11 & $\begin{array}{c}* * \\
10.01\end{array}$ & ص8 هـ = 3488739+43415198س هـ & | (2) أعداد الأغنام والماعز \\
\hline 3.41 & 87.72 & 99.964 & $\begin{array}{c}* * \\
9.998\end{array}$ & صه هـ = 9075.615+189176.4س هـ & إن إنتاج لحوم الماشية \\
\hline 4.61 & 78.12 & 50.142 & $\begin{array}{c}* * \\
7.081\end{array}$ & صه هـ = 10477.48+138005.5س هـ & (4) إنتاج لحوم الأغنام و الماعز \\
\hline 3.40 & 83.76 & 72.20 & $\begin{array}{c}* * * \\
8.497\end{array}$ & ص8 هـ & (5) أستهلاك لحوم الماشية \\
\hline 6.63 & 7.53 & 1.141 & $\begin{array}{c}* \star * \\
1.068 \\
* *\end{array}$ & ص8 = = 12.588+81.5س هـ & (6) كمية واردات لحوم المانشية \\
\hline
\end{tabular}


Ahmed, N. A. et al.

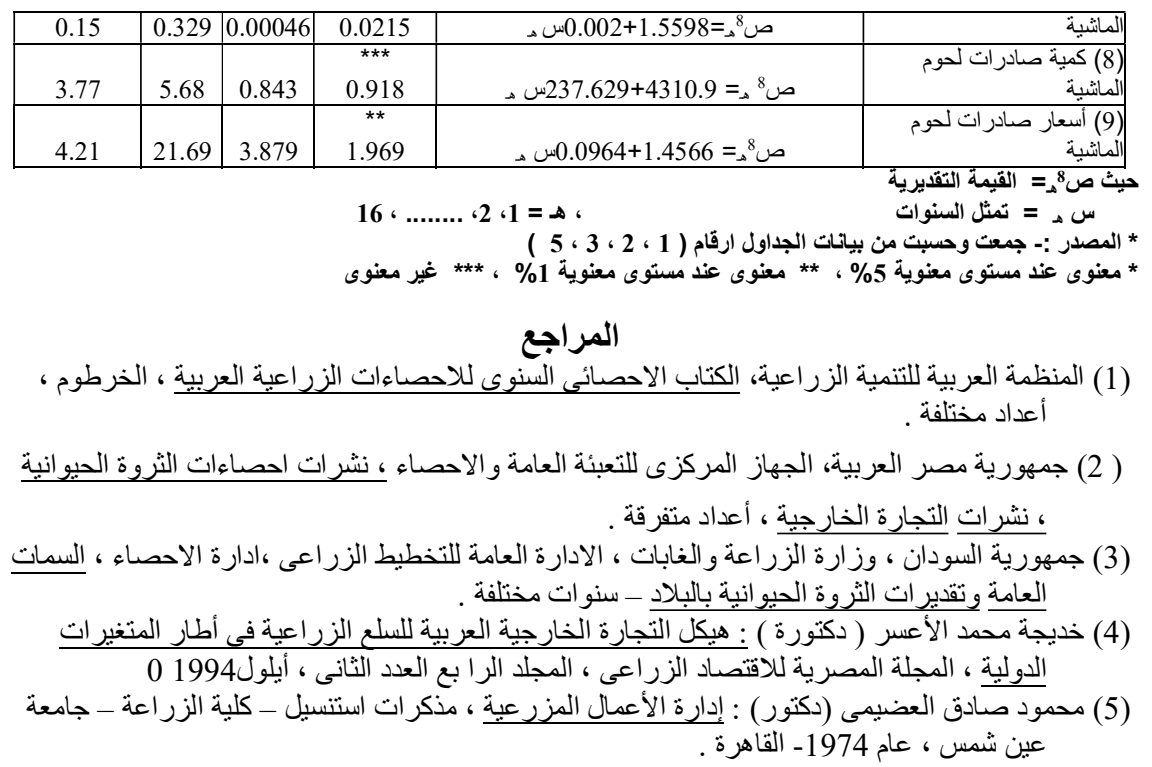

6) FAOSTAT, Food and Agricultural Organization of the United Nations .( http://food, stat .external .fao.org.

\section{AN ANALYTICAL STUDY FOR THE POSITIVE EFFECTS OF THE INTEGRATION BETWEEN EGYPT AND SUDAN IN THE FIELD OF RED MEAT AND ITS EFFECT ON THE PRICE MEAT IN EGYPT.}

Ahmed, N. A. ; M.A. Marry; A. S. Abdelwahab

Agricultural Economics Institute, Agricultural Research Center

\section{ABSTRACT}

The integration between Egypt and Sudan in the field of red meat to be achieved the self - sufficient and increase the per capita of the animal protein . The study showed that, there is a deficit in the red meat in Egypt during the period ( 2001-2005) amounted 123.5 thousand ton valued LE 202.36 million dollars, On the other hand, the Sudan has achieved a surplus amounted 5 thousand ton valued 12.94 million dollars .

The study showed that , the animal wealth in Sudan represented 4.2 Folds compare to it in Egypt. The production of red meat in Egypt increased from 304 thousand ton in 1990 to 590 thousand ton in 2005 . The annual increase amounted 17.23 thousand ton during the some said mentioned period ,while the consumption increase from 460.19 thousand ton in 1990 to 794.42 thousand ton in 2005 . So, the self -.Sufficient 
represented $66 \%$ in 1990 increased to $82.58 \%$ in 2005 . The average of per capita for the red meat amounted $28.5 \mathrm{gm} /$ day during the period (19902005).On the there hand, the red meat production in Sudan amounted 218.17 thousand ton in 1990 increased to 325 thousand ton in 2005 . The average of annual increase amounted 9 thousand ton. It is also noticed that, the consumption average 218.18 thousand ton in 1990 increased to 323.77 thousand ton in 2005. So, the self - sufficient of red meat represented $100 \%$, while the per capita average of red meat amounted $44.36 \mathrm{gm} /$ day during the period

(1990-2005) .The study reached to the following recommendation, To activate the integration between Egypt and Sudan in the activity of red meat. To increase the investments in this field and make transportation modern and prepared means available between the two countries. To make full use of the available natural resources and wealth. To increase the animal production and frozen meat in law prices suitable to the Egyptian consumers. 